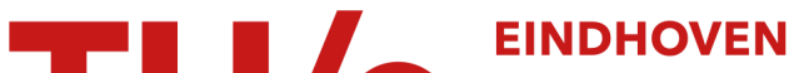 \\ UNIVERSITY OF \\ TECHNOLOGY
}

\section{Structures and burning velocities of flames in iron aerosols}

\author{
Citation for published version (APA): \\ Hazenberg, T., \& van Oijen, J. A. (2021). Structures and burning velocities of flames in iron aerosols. \\ Proceedings of the Combustion Institute, 38(3), 4383-4390. https://doi.org/10.1016/j.proci.2020.07.058
}

\section{Document license: \\ TAVERNE}

DOI:

10.1016/j.proci.2020.07.058

\section{Document status and date:}

Published: 01/01/2021

\section{Document Version:}

Publisher's PDF, also known as Version of Record (includes final page, issue and volume numbers)

\section{Please check the document version of this publication:}

- A submitted manuscript is the version of the article upon submission and before peer-review. There can be important differences between the submitted version and the official published version of record. People interested in the research are advised to contact the author for the final version of the publication, or visit the DOI to the publisher's website.

- The final author version and the galley proof are versions of the publication after peer review.

- The final published version features the final layout of the paper including the volume, issue and page numbers.

Link to publication

\section{General rights}

Copyright and moral rights for the publications made accessible in the public portal are retained by the authors and/or other copyright owners and it is a condition of accessing publications that users recognise and abide by the legal requirements associated with these rights.

- Users may download and print one copy of any publication from the public portal for the purpose of private study or research.

- You may not further distribute the material or use it for any profit-making activity or commercial gain

- You may freely distribute the URL identifying the publication in the public portal.

If the publication is distributed under the terms of Article 25fa of the Dutch Copyright Act, indicated by the "Taverne" license above, please follow below link for the End User Agreement:

www.tue.nl/taverne

Take down policy

If you believe that this document breaches copyright please contact us at:

openaccess@tue.nl

providing details and we will investigate your claim. 


\title{
Structures and burning velocities of flames in iron aerosols
}

\author{
T. Hazenberg*, J.A. van Oijen \\ Mechanical Engineering, Eindhoven University of Technology, Eindhoven, the Netherlands
}

Received 6 November 2019; accepted 2 July 2020

Available online 12 September 2020

\begin{abstract}
The steady flame propagation through a non-volatile fuel suspension is studied. An Eulerian description is used for the gas-phase, while particles are tracked in a Lagrangian framework. The gas-phase model includes both species transport and energy conservation equations. Moreover, expansion of the gas-phase, including particle slip velocity, is taken into account. Gas-phase properties are realistically dependent on temperature and composition. The particle model includes both the transport of oxidizer and surface kinetics. Lastly, a consistent formulation is used for the exchange of mass between the phases. When the particle conversion rate is diffusion-limited, the burning velocity is found to be dependent on local oxygen concentration. Moreover, the effect is sufficiently strong, such that the maximum burning velocity is found at fuel-lean conditions. This demonstrates that both energy and species transport equations in the gas phase and dispersed phase equations must be solved together.

(C) 2020 The Combustion Institute. Published by Elsevier Inc. All rights reserved.
\end{abstract}

Keywords: Iron; Dispersed-phase flame; Propagation; Eulerian-Lagrangian

\section{Introduction}

Bergthorson et al. [1] proposed metal fuels as a carbon-free energy carrier. As a metal fuel, iron has some promising properties. Namely, during combustion, the temperature of a particle does not exceed the boiling temperature of iron. As a result, iron burns heterogeneously and the combustion products are micron-sized particles. These micronsized particles can be captured, and reduced using solar and wind energy [1,2]. Therefore, a carbonfree closed-cycle can be formed.

\footnotetext{
* Corresponding author.

E-mail address: t.hazenberg@tue.nl (T. Hazenberg).
}

To develop reliable metal fuel burners, a thorough understanding of metal (solid) phase combustion is required. To this end, experiments have been performed to measure the burning velocity of various metals in various setups [3-9]. While these experiments have aided in understanding metal combustion, they have also raised new questions. Julien et al. [8] compared the measured burning velocity of aluminum powders on four different setups and found a variation of $50 \%$. The large scatter is probably the result of the unknown effects of flow configuration on burning velocity.

Concurrently, several models have been developed for the analysis of burning velocity. Goroshin et al. [10] derived two analytical models, either valid in the fuel-lean limit (no equation for oxygen 
is solved), or in the fuel-rich limit (particle size remains constant). Goroshin et al. [11] extended the fuel-lean limit model to include binary particle suspensions. More recently, Goroshin et al. [12] developed a numerical model for the fuel-lean limit. In contrast to the two previous models, the dispersed phase is modeled with a discrete description instead of a continuous one. Sidorov and Shevchuk [13] developed a model similar to the lean model by Goroshin et al. [10]. However, the particle temperature is assumed to be equal to the gas temperature in the preheat zone. Soo et al. $[14,15]$ developed a numerical model for the combustion of a single metal particle and the transient propagation of metal flames. In their particle model, the reaction rate of a single particle is the combined effect of oxygen diffusion to the particle surface and a one-step surface reaction. During combustion, the fuel particles shrink and the combustion products vanish. This is more representative of the vapor phase combustion of e.g. aluminum. To simulate the propagation of flames, their particle model is coupled to a density-weighted finite-difference description of the gas-phase. In the gas-phase solver, equations for both oxygen and temperature were solved.

In this work, a novel numerical model is developed, in which no assumptions about fuel-lean or rich conditions are made. The mass and energy transport between the dispersed and gaseous phase is formulated consistently. As in the work of Soo et al. [14], the conversion rate is controlled by both the rate of oxygen diffusion and surface reactions. However, in our implementation, the combustion products do not vanish. As such, mass and energy are conserved between the dispersed and continuous phases. Furthermore, the expansion of the gas phase is taken into account, together with the resulting slip velocity on the particles. Finally, the gas-phase is described by realistic, temperature and composition-dependent properties. While the developed model is more generally applicable, we limit ourselves to the combustion of iron.

\section{Model description}

Dispersed fuels can combust in different regimes depending on their thermophysical properties. Unlike most hydrocarbon fuels, iron does not become volatile during combustion. As a result, the combustion takes place at the surface of the iron particles. Furthermore, oxygen is consumed from the gas-phase and remains in the particles after it reacts, forming iron-oxide. To model the dispersed phase combustion of iron powder flames, an Eulerian-Lagrangian method is employed.

\subsection{Particle modeling}

The position $x_{p}$ and velocity $u_{p}$ of the iron particles is tracked. Only drag forces are considered and forces due to gravity are neglected (e.g. Sirignano [16]),

$$
\frac{\mathrm{d} x_{p}}{\mathrm{~d} t}=u_{p}, \quad \frac{\mathrm{d} u_{p}}{\mathrm{~d} t}=\frac{3}{4} \frac{C_{\mathrm{D}} \rho}{d_{p} \rho_{p}}\left|u-u_{p}\right|\left(u-u_{p}\right)
$$

in which, $\rho$ is the density, $C_{\mathrm{D}}$ is the coefficient of drag, and $d_{p}$ is the diameter of the particle. Subscript ${ }_{p}$ indicates properties of the particles, while no subscript is used for gas properties.

Oxygen in the carrier gas can react with the particles, at the surface of the particle. Therefore, oxygen in the air has to be transported from outside the particle boundary layer to the particle surface. As a result, both the rate of oxygen diffusion $k_{d}$ and the rate of reaction $k_{r}$ can be rate-limiting. The conversion rate is modeled assuming a quasi-steady-state boundary layer (e.g. Frank-Kamenetskii [17]),

$$
\frac{\mathrm{d} m_{p}}{\mathrm{~d} t}=\rho Y_{O_{2}} A_{d} k_{d} \mathrm{Da}^{*}, \quad \frac{\mathrm{d} m_{p, \mathrm{Fe}}}{\mathrm{d} t}=-\frac{1}{s} \frac{\mathrm{d} m_{p}}{\mathrm{~d} t} .
$$

Here, $m_{p}$ is the particle mass, $\rho Y_{O_{2}}$ is the density of oxygen in the carrier gas. The consumption of the unreacted iron mass $m_{p, \mathrm{Fe}}$ is computed using the stoichiometric ratio $s$, in kilogram oxygen per kilogram iron. A normalized Damköhler number is introduced, defined as $\mathrm{Da}^{*}=A_{r} k_{r} /\left(A_{r} k_{r}+A_{d} k_{d}\right)$.

Here, reactive $A_{r}$ and diffusive $A_{d}$ areas were introduced. We included these such that the diffusive and reactive area can vary independently from the particle surface area $A_{p}$. For example, Sun et al. [4] presume that a liquid iron-oxide shell surrounds an iron core and that the adsorption of oxygen into the iron-oxide shell is the ratelimiting step. Under this assumption, an appropriate choice would be $A_{d}=A_{p}$ and (to ensure $\mathrm{Da}^{*} \rightarrow 0$ as $\left.m_{p, \mathrm{Fe}} \rightarrow 0\right) A_{r}=\left(m_{p, \mathrm{Fe}} / m_{p}\right) A_{p}$. However, in this work, we follow the hypothesis made by Bergthorson et al. [1], where the iron-oxide forms a porous shell around an unreacted iron core on which the surface reaction takes place. Additionally, it is assumed that this porous shell does not inhibit diffusion of oxygen towards the iron core. The reactive and diffusive areas are then defined as $A_{d}=A_{r}=\pi d_{p, \mathrm{Fe}}^{2}$, with $d_{p, \mathrm{Fe}}$ the diameter of the iron core.

Due to a temperature difference between the particle and gas exchange of energy takes place. Like for mass transfer, a quasi-steady-state boundary layer is assumed. Therefore, the convective heat transfer and enthalpy exchange due to the reaction of oxygen takes place according to

$\frac{\mathrm{d} H_{p}}{\mathrm{~d} t}=k_{c} A_{p}\left(T_{p}-T\right)+\frac{\mathrm{d} m_{p}}{\mathrm{~d} t} h_{O_{2}}$,

in which $H_{p}$ is the enthalpy of the particle, $k_{c}$ is the convective energy transfer rate, $T$ is the temperature, and $h_{\mathrm{O}_{2}}$ is the enthalpy of the reacting oxygen. 


\subsubsection{Constitutive equations}

The coefficient of drag is provided by an empirical relationship for low Reynolds number [18]:

$C_{D}=\frac{24}{\operatorname{Re}}\left(1+0.15 \operatorname{Re}^{0.687}\right)$,

in which Re is the Reynolds number of the particle $\left(\operatorname{Re}=\left|u-u_{p}\right| d_{p} / v_{f}\right)$ with $v_{f}$ the kinematic viscosity of the carrier gas in the particle film layer.

The diffusive and conductive transfer rates are based on a spherical particle, $k_{d}=\operatorname{Sh} \mathcal{D}_{O_{2}, f} / d_{p, \mathrm{Fe}}$ and $k_{c}=\mathrm{Nu} \lambda_{f} / d_{p}$. Where, $\mathcal{D}_{O_{2}, f}$ is the film layer diffusivity of oxygen, and $\lambda_{f}$ is the film layer thermal conductivity. For the calculation of the Sherwood ( $\mathrm{Sh})$ and Nusselt $(\mathrm{Nu})$ number, we assume that $\operatorname{Re} \ll 1$ and no Stefan flow is present, such that $\mathrm{Sh}=2$ and $\mathrm{Nu}=2$ (e.g. Clift et al. [18]).

The film transport properties $\left(\lambda_{f}, \mathcal{D}_{O_{2}, f}\right.$, and $\left.v_{f}\right)$ are evaluated at the film temperature $T_{f}=$ $T_{p}+1 / 3\left(T-T_{p}\right)[19]$, using the empirical relations: [20]

$\lambda=A_{0} c_{\mathrm{p}}\left(\frac{T}{298}\right)^{n_{0}}, \quad v=A_{1} \frac{c_{\mathrm{p}}}{\rho}\left(\frac{T}{298}\right)^{n_{1}}$.

Where, $c_{\mathrm{p}}$ is the heat capacity, evaluated from the often used NASA polynomials. The diffusivity $\mathcal{D}_{\mathrm{O}_{2}, f}$ is computed assuming constant Lewis number: $\mathcal{D}_{O_{2}, f}=\lambda_{f} / \rho_{f} \operatorname{Le}_{O_{2}} c_{\mathrm{p}, f}$.

For the surface reaction rate, an Arrhenius type relation is assumed, $k_{r}=k_{\infty} \exp \left(-E_{a} /\left(R_{u} T_{p}\right)\right)$. With $E_{a} / R_{u}$ the activation temperature and $k_{\infty}$ the pre-exponential. The particle temperature relates to the particle enthalpy via

$H_{p}=m_{p} C_{\mathrm{p}}\left(T_{p}-T_{\mathrm{ref}}\right)-m_{p} Y_{\mathrm{FeO}} \Delta h_{c}$,

in which $\Delta h_{c}$ is the combustion enthalpy, $C_{\mathrm{p}}$ is the particle heat capacity, and $Y_{\mathrm{FeO}}$ is the iron-oxide mass fraction in the particle $\left(Y_{\mathrm{FeO}}=1-m_{p, \mathrm{Fe}} / m_{p}\right)$.

To relate particle volume to surface area and radius, a perfect sphere is assumed. To compute the particle volume $V_{p}$ from the particle composition, ideal mixing of phases is assumed:

$V_{p}=\frac{m_{p, \mathrm{Fe}}}{\rho_{\mathrm{Fe}}}+\frac{m_{p}-m_{p, \mathrm{Fe}}}{\rho_{\mathrm{FeO}}}$,

in which $\rho_{\mathrm{Fe}}$ and $\rho_{\mathrm{FeO}}$ are the density of metal and metal-oxide respectively. Finally, the iron core diameter is provided by,

$d_{p, \mathrm{Fe}}=\left(\frac{6}{\pi} \frac{m_{p, \mathrm{Fe}}}{\rho_{\mathrm{Fe}}}\right)^{\frac{1}{3}}$.

\subsection{Gas-phase modeling}

The system of equation is described by those of a 1D freely propagating flat flame, assuming the low Mach number combustion approximation in $1 \mathrm{D}$ [21]. To solve these equations, the finite-volume solver CHEM1D is used with solution strategies described by Somers [22]. This solver has been used to compute burning velocities in many studies, e.g.
[22-24]. Mass and species conservation equations are given by

$$
\begin{aligned}
& \frac{\partial \rho u}{\partial x}=S_{m} \\
& \frac{\partial \rho u Y_{i}}{\partial x}-\frac{\partial}{\partial x}\left(\frac{\lambda}{c_{\mathrm{p}} \mathrm{Le}_{i}} \frac{\partial Y_{i}}{\partial x}\right)=\delta_{i, k} S_{m},
\end{aligned}
$$

in which, $S_{m}$ is the mass exchange with the dispersed phase, and $Y_{i}$ is the mass fraction of species $i$. Since there is only an exchange of oxygen, the $k$ in the Kronecker delta $\left(\delta_{i, k}\right)$ equals the index of oxygen. The energy equation is given by

$\frac{\partial \rho u h}{\partial x}+\frac{\partial q}{\partial x}=S_{h}$,

with

$q=-\frac{\lambda}{c_{\mathrm{p}}} \frac{\partial h}{\partial x}+\sum_{i=1}^{N_{s}}\left(\frac{1}{\mathrm{Le}_{i}}-1\right) h_{i} \frac{\partial Y_{i}}{\partial x}$,

in which, $S_{h}$ is the enthalpy exchange between the phases, and $q$ is the transport of enthalpy due to mass and thermal diffusion in the gas phase.

The coupling between the phases follows a similar methodology as in Sacomano-Filho et al. [24]. During the particle tracking the most recent solution of the gas phase is used. A single particle is tracked until it leaves the computational domain. It is not necessary to track all physical particles individually, because there is no particle to particle interaction, and we solve a steady problem, which means that the time evolution of every particle is identical. Therefore, a single computational particle can represent all real particles by multiplying its effect on the gas phase with the particle number flux $\dot{N}_{p}=\dot{m} / m_{p, 0}$, where $\dot{m}$ is the mass flux of particles at the inlet and $m_{p, 0}$ is the initial mass of a single particle. The mass and heat exchange between the particles and gas in a single finite-volume cell $k$ can therefore be written as

$S_{m, k}=\dot{N}_{p} \frac{\Delta m_{p, k}}{V_{k}}, \quad S_{h, k}=\dot{N}_{p} \frac{\Delta H_{p, k}}{V_{k}}$,

in which $V_{k}$ is the volume of cell $k$, and $\Delta m_{p, k}$ and $\Delta H_{p, k}$ are the integrated mass and enthalpy changes of a single particle during its residence in cell $k$.

The particle model is integrated using an adaptive Runge-Kutta solver. Verner's 5th and 6th order pair is used to adaptively choose the time step [25-27]. To ensure that $S_{m}$ and $S_{h}$ are captured with sufficient accuracy, a conservative minimum of 50 time steps per finite-volume cell for the Lagrangian solver is enforced.

The developed code is tested extensively. Since the Eulerian and Lagrangian solvers are alternated, the Eulerian solver can only converge if the Lagrangian solution does not change. Therefore, the convergence of the solution is ensured by computing the normalized residue of the discretized equations in the Eulerian framework. The L2-norm of 
Table 1

Simulation parameters.

\begin{tabular}{lll}
\hline Variable & Value & unit \\
\hline$s$ & 0.28 & - \\
$\rho_{\mathrm{Fe}}$ & 7.874 & $\mathrm{~g} / \mathrm{cm}^{3}$ \\
$\rho_{\mathrm{FeO}}$ & 5.745 & $\mathrm{~g} / \mathrm{cm}^{3}$ \\
$\mathrm{C}_{p}$ & 0.677 & $\mathrm{~J} /(\mathrm{g} \mathrm{K})$ \\
$\Delta h_{c}$ & 2906 & $\mathrm{~J} / \mathrm{g}$ \\
$k_{\infty}$ & $75.0 \times 10^{7}$ & $\mathrm{~cm} / \mathrm{s}$ \\
$E_{a} / R_{u}$ & $14.4 \times 10^{3}$ & $\mathrm{~K}$ \\
\hline
\end{tabular}

this residue is reduced to $1.0 \times 10^{-10}$ to ensure an accurate solution. In post-processing studies, local and global conservation of mass and energy between the two phases is validated.

\section{Steady flame propagation}

The model presented above is used to simulate steady flame propagation of iron dispersed in air. For the particles, the parameters from Table 1 are used. The stoichiometric coefficient $s$ is based on the reaction: $\mathrm{Fe}+\mathrm{O}->\mathrm{FeO}$, matching densities of iron and iron-oxide are used. In the Supplementary Materials results are included assuming different oxides as end products. As a first step, a monodispersed powder with initial size $d_{p, 0}=10 \mu \mathrm{m}$ is used. The reaction rate parameters $k_{\infty}$ and $E_{a}$ are chosen such that an iron particle auto ignites in air at a temperature of $850 \mathrm{~K}$, in agreement with observations from Breiter et al. [28]. The activation energy has been kept comparable to the value used by Soo et al. [15]. The combination of the chosen parameters results in a diffusion-limited reaction if $T_{p}>1200 \mathrm{~K}$. Besides the kinetic parameters, the heat capacity is also important for ignition. Because of this, the heat capacity is taken from iron near the auto-ignition temperature. However, the real heat capacity is not constant between room temperature and the stoichiometric flame temperature of iron. To ensure that the stoichiometric flame temperature still agrees with experimental observation, the heat-release of combustion $\left(\Delta h_{c}\right)$ is reduced to $2906 \mathrm{~J} / \mathrm{g}$ from $3700 \mathrm{~J} / \mathrm{g}$. Finally, the composition of the carrier gas is that of air and the pressure is taken at one bar. From the chosen parameters and inlet conditions, the fuel concentration $\rho_{\text {fuel }}$ at the stoichiometric fuel-equivalence ratio can be computed as $\rho_{\text {fuel, stoi }}=955 \mathrm{~g} / \mathrm{m}^{3}$.

A set of simulations is performed where $\phi$ is varied from 0.5 to 1.3 . Out of this set of simulations two are taken to explain the observed flame structures. Thereafter, the temperature at the outlet $T_{\infty}$ and the laminar burning velocity $S_{\mathrm{L}}$ for this range of $\phi$ will be discussed.

\subsection{Structures of iron flames}

The profiles of particle and gas temperature of an iron flame at $\phi=0.8$ and $\phi=1.0$ are shown in Fig. 1. We have defined $x=0$ where the gas and particle are at equal temperature, which coincides with $\partial^{2} T / \partial x^{2}=0$. Fresh air and particles are injected from the left. Initially, both particles and gas are at the unburned temperature of 300 $\mathrm{K}$. As in classical gas-phase flames, energy is conducted from the burnt gas to the unburned gas. As a result, the gas becomes warmer than the particles and heat is also transferred to the particles. The increase in particle temperature results in an increase of the surface reaction rate. This can also be seen in the bottom graph, where the normalized Damköhler number is shown. Near the flame center $(x=0), \mathrm{Da}^{*}$ approaches unity, indicating the conversion rate downstream is limited by diffusion. For $x>0$, heat release due to combustion increases $T_{p}$ beyond the gas temperature.

If the solutions from $\phi=0.8$ and $\phi=1.0$ are compared it can be noted that the maximum particle temperature is larger than the maximum gas temperature if $\phi<1.0$. However, if $\phi \geq 1.0$ then the maximum particle temperature is limited to the maximum gas temperature. Goroshin et al. [10] postulated this behavior and the model from Soo et al. [14] also showed this behavior. Both these works also indicate that this transition occurs at $\phi=1.0$, which matches the observations from our model. While not shown, at fuel-lean conditions the observed maximum particle temperature increases as $\phi$ decreases. An explanation based on diffusion-limited combustion may seem obvious, since $\mathrm{Da}^{*} \approx 1$. However, such an explanation can not easily incorporate effects of varying oxygen concentration, gas temperature and transport coefficients. Neither the oxygen concentration (as will be shown later) nor the gas temperature is comparable to the inlet conditions at the location of the maximum particle temperature. The interplay of these factors influencing the maximum particle temperature is rather complex and space constrains do not allow for an in depth discussion here.

For the continuum model to be valid, there should be sufficient number of particles in the flame front at the same time. When the particle concentration is too low, discrete effects become important. At inlet conditions, the average inter-particle spacing can be computed as $L_{p p}=\left(S_{\mathrm{L}} / \dot{N}_{p}\right)^{\frac{1}{3}}=$ $0.18 \mathrm{~mm}$ and $L_{p p}=0.16 \mathrm{~mm}$ for $\phi=0.8$ and $\phi=$ 1.0. This means that $d_{p} \ll L_{p p}$, such that the assumption of no inter-particle interaction is valid. Furthermore, the thermal flame thickness (based on the steepest gradient of $T$ ) is $\delta_{f}=1.25 \mathrm{~mm}$ and $\delta_{f}=1.45 \mathrm{~mm}$ for $\phi=0.8$ and $\phi=1.0$, respectively. As such $L_{p p} \ll \delta_{f}$, and therefore, there are many particles in the flame front. Finally, the discreteness parameter from Goroshin et al. [12], defined as $\tau_{c}=t_{b} \lambda / \rho c_{\mathrm{p}} L_{p p}^{2}=4$, indicates that the combustion duration of a single particle is longer than the characteristic heat-transfer time. From these observations, we conclude that discrete effects in these 

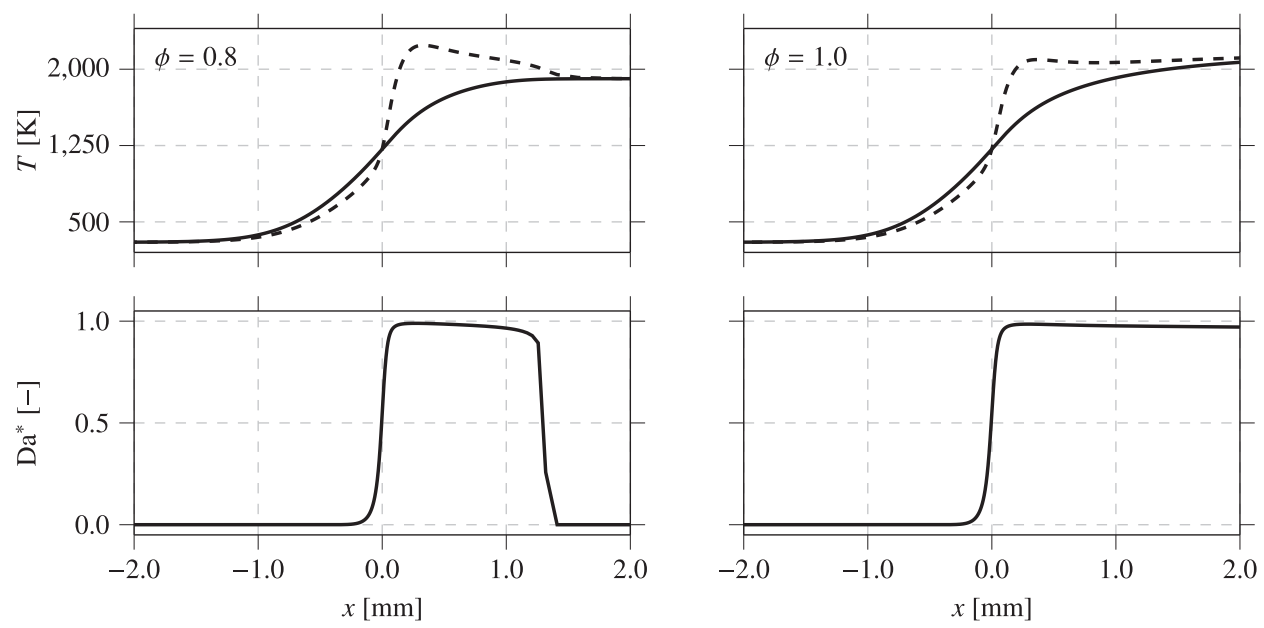

Fig. 1. In the top graphs $T$ (solid) $T_{p}$ (dashed), in the bottom graphs the $\mathrm{Da}^{*}$ is shown. The left graphs are at $\phi=0.8$ and the right at $\phi=1.0$.

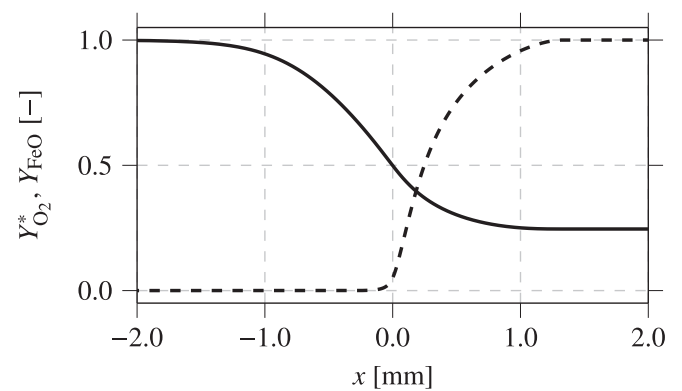

Fig. 2. Profile of $Y_{\mathrm{O}_{2}}^{*}$ (solid) and $Y_{\mathrm{FeO}}$ (dashed) at $\phi=$ 0.8 .

simulations are likely negligible, and the continuum approximation is valid.

Figure 2 shows the iron-oxide fraction of particles $\left(Y_{\mathrm{FeO}}\right)$ and normalized oxygen fraction, $Y_{\mathrm{O}_{2}}^{*}=$ $Y_{\mathrm{O}_{2}} / Y_{\mathrm{O}_{2}, 0}$. Since oxygen is diffusive, the normalized oxygen fraction starts to decrease before the particle burned fraction changes. Around $x=0.0$, the iron surface reaction increases fast, such that the reaction is limited by diffusion and $Y_{\mathrm{FeO}}$ increases rapidly. The result is that local stoichiometry, near the flame center, is more fuel-rich than at inlet conditions. This implies that an overall fuel-lean flame can be stoichiometric or even fuel-rich in the reaction zone.

Based on the results of Fig. 2, an estimate of the error related to the neglected Stefan flow can be made. The Stefan flow is most significant when the difference in the mass fraction of oxygen between the particle surface and bulk is at a maximum. This occurs at the flame center, where the surface mass fraction $\left(Y_{\mathrm{O}_{2}, s}\right)$ is zero and $Y_{\mathrm{O}_{2}} \approx 0.15$. Using theory from droplet condensa-

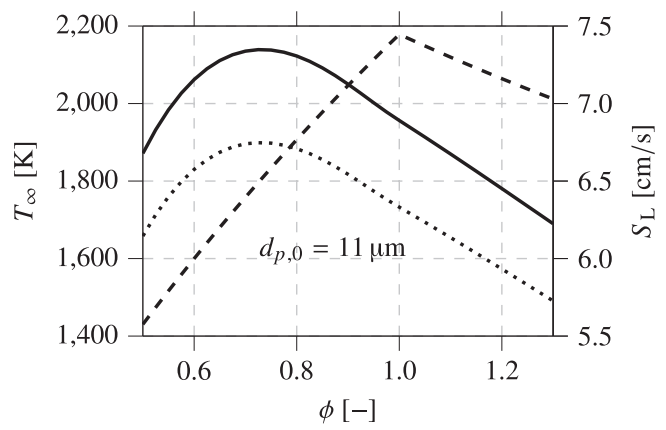

Fig. 3. Flame temperature $T_{\infty}$ (dashed), burning velocity $S_{\mathrm{L}}$ (solid), and burning velocity of larger particle $11 \mu \mathrm{m}$ (dotted) as a function of equivalence ratio $\phi$.

tion/evaporation [16], the Spalding number is computed as $B_{m}=\left(Y_{\mathrm{O}_{2}}-Y_{\mathrm{O}_{2}, s}\right) /\left(Y_{\mathrm{O}_{2}, s}-1\right)=-0.15$. The Sherwood number can then be corrected to include the Stefan flow, $\mathrm{Sh}^{*} / \mathrm{Sh}=\ln \left(1+B_{m}\right) / B_{m}=$ 1.08. This implies that the burn duration $\left(t_{b}\right)$ is reduced by $8 \%$, which corresponds to an increase of $4 \%$ in the burning velocity, since $S_{\mathrm{L}} \propto t_{b}^{-0.5}[6]$.

\subsection{Burning velocity and temperature}

In Fig. 3 the flame temperature and burning velocity are shown as a function of equivalence ratio. The maximum flame temperature $\left(\max \left(T_{\infty}\right)=2179 \mathrm{~K}\right)$ is found at stoichiometric $\left(\phi_{\max } T_{\infty}\right)$ conditions. Due to the chosen values of $\mathrm{C}_{p}$ and $\Delta h_{c}$, this is close to the thermal equilibrium calculations $(2229 \mathrm{~K})$ and experimental observations (1820-2410 K) of Tang et al. [6]. The lack of dissociation in the model explains, why the flame temperature is non-smooth at $\phi=1.0$. To both 
richer and leaner conditions, the flame temperature decreases almost linearly.

The observed burning velocity $S_{\mathrm{L}}$ ranges between 6.2 and $7.3 \mathrm{~cm} / \mathrm{s}$. At a stoichiometric mixture $S_{\mathrm{L}}=6.9 \mathrm{~cm} / \mathrm{s}$, which is close to experimental observations $(7.9 \mathrm{~cm} / \mathrm{s}$ to $11.3 \mathrm{~cm} / \mathrm{s}$, corrected for the parabolic flame front) from Tang et al. [6]. Furthermore, results for flames with a particle size of $11 \mu \mathrm{m}$ are also included. The burning velocity of these larger particles at a stoichiometric is $6.3 \mathrm{~cm} / \mathrm{s}$. Therefore, the burning velocity scales with $1 / d_{p, 0}$, in agreement with the experimental observation of Tang et al. [5], this is more clearly demonstrated in the Supplementary Materials.

The maximum of $S_{\mathrm{L}}$ is observed at $\phi \approx 0.7$ and reduces with a smooth curve on either side. The general trend is comparable to Sun et al. [3]. However, the equivalence ratio of maximum burning velocity $\left(\phi_{\max S_{L}}\right)$ has a significant shift. The shift in $\phi_{\max S_{\mathrm{L}}}$ is unexpected if compared to gas-phase flames, where $\phi_{\max S_{\mathrm{L}}}$ is found near $\phi_{\max T_{\infty}}$. In most gas-phase flames, $\phi_{\max S_{\mathrm{L}}} \approx \phi_{\max T_{\infty}} \approx 1$ due to the strong dependence of reaction rate on temperature (e.g. Law [21]). However, in these iron flames, the heat release is limited by diffusion of oxygen, if the particle is sufficiently hot (Fig. 1). After ignition, the combustion rate is only weakly dependent on temperature but strongly dependent on local oxygen concentration. As shown in Fig. 2, the oxygen mass fraction has already reduced (due to diffusion) before any noticeable surface reaction has taken place. Therefore, we hypothesize that the shift in $\phi_{\max S_{\mathrm{L}}}$ is the result of a strong dependence of the reaction rate on oxygen, and the lack of diffusion of the fuel particles.

\subsection{A new flame regime?}

To verify this hypothesis, two sets of simulations are performed. In the first set, the importance of gas-phase transport is studied. The Lewis number is changed $\left(\mathrm{Le}_{\mathrm{O}_{2}}=2\right)$, and to maintain a similar Damköhler number the Sherwood number is changed accordingly $(\mathrm{Sh}=4, \mathrm{Nu}=2)$. The second set is used to study the importance of a diffusionlimited conversion rate. To achieve this the rate coefficient has been altered $\left(k_{\infty}^{*}=2 k_{\infty} \times 10^{-2}\right)$, such that the reaction rate is comparable to the diffusion rate at the stoichiometric flame temperature. The normalized burning velocity $S_{\mathrm{L}}^{*}=S_{\mathrm{L}} / \max \left(S_{\mathrm{L}}\right)$ of these simulations is depicted in Fig. 4. The results with the original parameters are included as a reference.

First, the results from the altered Lewis number will be analyzed. Due to the increased Lewis number, oxygen diffusion is reduced. Therefore, the mass fraction oxygen, near $x=0$, is higher, as depicted in Fig. 5. As shown in Fig. 6, the reaction rate is still limited by diffusion. Since the mass diffusion is not very sensitive to temperature, the conversion rate is (almost) solely dependent on the oxy-

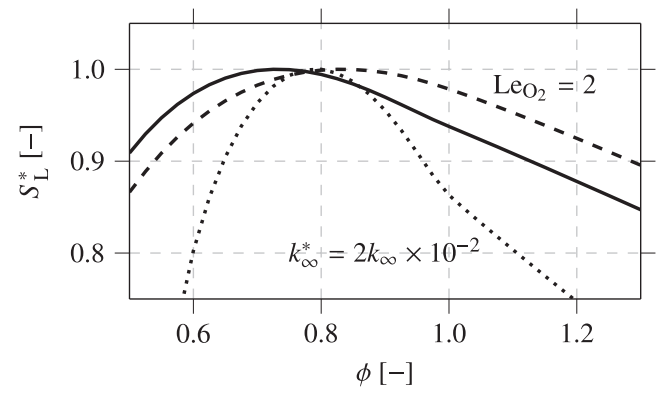

Fig. 4. $S_{\mathrm{L}}^{*}$ as function of equivalence ratio. Reference (solid), $\mathrm{Le}_{\mathrm{O}_{2}}=2$ (dashed), and $k_{\infty}^{*}=2 k_{\infty} \times 10^{-2}$ (dotted).

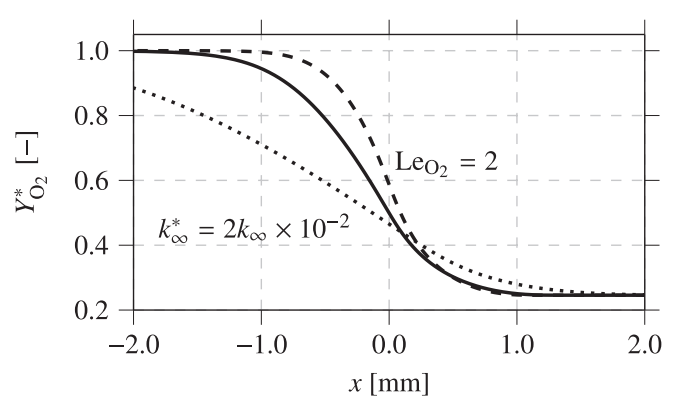

Fig. 5. Profile of $Y_{\mathrm{O}_{2}}^{*}$, at $\phi=0.8$. Reference (solid), $\mathrm{Le}_{\mathrm{O}_{2}}=2$ (dashed), and $k_{\infty}^{*}=2 k_{\infty} \times 10^{-2}$ (dotted).

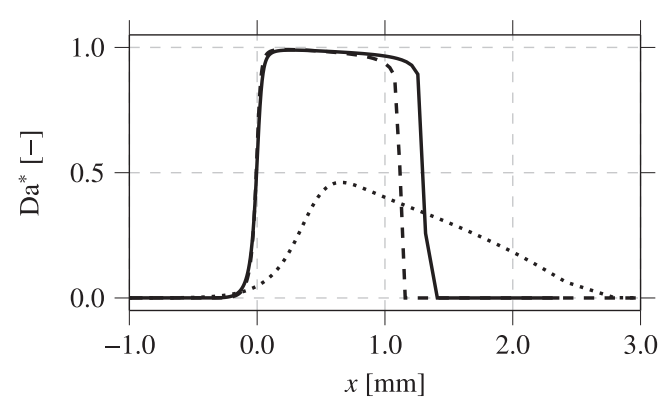

Fig. 6. Profile of $\mathrm{Da}^{*}$, at $\phi=0.8$. Reference (solid), $\mathrm{Le}_{\mathrm{O}_{2}}=2$ (dashed), and $k_{\infty}^{*}=2 k_{\infty} \times 10^{-2}$ (dotted).

gen mass fraction. Therefore, the increased oxygen mass fraction strongly increases the conversion rate of iron. Of course, an increase in reaction rate will also increase the burning velocity. The result is a shift of $\phi_{\max S_{\mathrm{L}}}$ towards a stoichiometric mixture, due to the reduced oxygen diffusivity (or increased $\mathrm{Le}_{\mathrm{O}_{2}}$ ). This demonstrates the importance of differential diffusion between $O_{2}$ and fuel in dispersed flames.

Second, the results for $k_{\infty}^{*}=2 k_{\infty} \times 10^{-2}$ are discussed. From Fig. 5, it can be seen that the mass fraction of oxygen near $x=0$ is still comparable to the reference case. Furthermore, the shape of the 
oxygen profile has been maintained but elongated. This is the result of a reduced $S_{\mathrm{L}}$ (lower reaction rate), resulting in an increased $\delta_{f}$ by a factor of approximately $S_{\mathrm{L}, \mathrm{ref}} / S_{\mathrm{L}}$. For these results, $\mathrm{Da}^{*}$ does not approach unity but remains below 0.5 , this indicates that particle conversion takes place closer to the kinetic regime. Therefore, the particle conversion rate is more sensitive to temperature than in the initial simulations. Since the flame temperature is highest at $\phi=1$, the concentration of maximum burning velocity shifts towards stoichiometric conditions. The impact of the kinetic parameters is likely why Soo et al. [15] find $\phi_{\max S_{\mathrm{L}}} \approx 1$, since $\mathrm{Da}^{*} \ll 1$.

\section{Discussion and conclusion}

To simulate the heterogeneous combustion of iron aerosols, an Eulerian-Lagrangian model is developed. Using this model the burning velocity as a function of fuel equivalence ratio is investigated. Unexpectedly, the maximum burning velocity is found at lean conditions. We postulated that this is the result of differential diffusion between fuel and oxidizer, and a diffusion-limited surface reaction.

While a fundamental explanation is provided for the unexpected location of $\phi_{\max S_{\mathrm{L}}}$, it has not yet been confirmed by experimental observations. We hypothesize that this discrepancy is partly due to the use of a mono-sized particle distribution in the simulations. When using a more realistic particle size distribution, groups of similarly sized particles will ignite sequentially, smearing out the consumption of oxygen and heat release. The smallest particles ignited first, would then enjoy the abundance of oxygen of a lean flame, and at the same time experience the increased heating rate of a stoichiometric flame. As a result, the equivalence ratio at which the highest burning velocity is observed could shift towards stoichiometric conditions. Further studies could investigate this hypothesis by using synthetic particle size distributions.

In this work, a basic model is presented, which captures the fundamentals of iron dust flames. To achieve this, various assumptions were carefully made. However, there is ample opportunity for further studies to investigate relaxed assumptions. A non-exhaustive list of possible studies are: (1) defining the particle heat capacity as composition and temperature dependent such that phase transitions can be captured, (2) extend the particle model to include different oxides or include an oxide shell which inhibits diffusion, (3) investigating the effect of particle size distribution on flame speed and structure. Furthermore, the present model allows us to use arbitrary gas-phase reaction mechanisms, which opens the way to predict nitrogen oxide emissions and to study hybrid flames in gas-solid fuel mixtures.

\section{Declaration of Competing Interest}

None.

\section{Supplementary material}

Supplementary material associated with this article can be found, in the online version, at doi: 10 . 1016/j.proci.2020.07.058.

\section{References}

[1] J.M. Bergthorson, S. Goroshin., M.J. Soo, P. Julien, J. Palecka, D.L. Frost, D. Jarvis, Appl. Energy 160 (2015) 368-382.

[2] J.M. Bergthorson, Prog. Energy Combust. Sci. 68 (2018) 169-196

[3] J.H. Sun, R. Dobashi, T. Hirano, Symp. (Int.) Combust. 27 (1998) 2405-2411.

[4] J.H. Sun, R. Dobashi, T. Hirano, Combust. Sci. Technol. 150 (2000) 99-114.

[5] F.D. Tang, S. Goroshin, A.J. Higgins, J.H. Lee, Proc. Combust. Inst. 32 (2009) 1905-1912.

[6] F.D. Tang, S. Goroshin, A.J. Higgins, Proc. Combust. Inst. 33 (2011) 1975-1982.

[7] P. Julien, S. Whiteley, S. Goroshin, M.J. Soo, D.L. Frost, J.M. Bergthorson, Proc. Combust. Inst. 35 (2015) 2431-2438.

[8] P. Julien, S. Whiteley, M.J. Soo, S. Goroshin, D.L. Frost, J.M. Bergthorson, Proc. Combust. Inst. 36 (2017) 2291-2298.

[9] M. McRae, P. Julien, S. Salvo, S. Goroshin, D.L. Frost, J.M. Bergthorson, Proc. Combust. Inst. 37 (2019) 3185-3191.

[10] S. Goroshin, M. Bidabadi, J.H. Lee, Combust. Flame 105 (1996) 147-160.

[11] S. Goroshin, M. Kolbe, J.H. Lee, Proc. Combust. Inst. 28 (2000) 2811-2817.

[12] S. Goroshin, F.D. Tang, A.J. Higgins, Phys. Rev. E 84 (2011).

[13] A.E. Sidorov, V.G. Shevchuk, Combust. Explos. Shock Waves 47 (2011) 518-522.

[14] M.J. Soo, S. Goroshin, J.M. Bergthorson, D.L. Frost, Propellants Explos. Pyrotech. 40 (2015) 604-612.

[15] M.J. Soo, K. Kumashiro, S. Goroshin, D.L. Frost, J.M. Bergthorson, Proc. Combust. Inst. 36 (2017) 2351-2358.

[16] W.A. Sirignano, Fluid Dynamics and Transport of Droplets and Sprays, Cambridge University Press, 2012.

[17] D.A. Frank-Kamenetskii, J.P. Appleton, Diffusion and Heat Exchange in Chemical Kinetics, Plenum Press, 1969.

[18] R. Clift, J.R. Grace, M.E. Weber, Bubbles, Drops, and Particles, Dover Publications, 1978.

[19] G. Hubbard, V. Denny, A. Mills, Int. J. Heat Mass Transf. 18 (1975) 1003-1008.

[20] M. Smooke, R. Bilger, Reduced Kinetic Mechanisms and Asymptotic Approximations for Methane-Air Flames, Lecture notes in physics, Springer-Verlag, 1991.

[21] C.K. Law, Combustion Physics, 2006, Cambridge University Press.

[22] L.M.T. Somers, Reliab. Eng. Syst. Saf. (1994). 
[23] M. Goswami, S.C. Derks, K. Coumans, W.J. Slikker, M.H. de Andra, R.J. Bastiaans, C.C. Luijten, L.P.H. de Goey, A.A. Konnov, Combust. Flame 160 (2013) 1627-1635.

[24] F.L. Sacomano-Filho, N. Speelman, J.A. van Oijen, L.P.H. de Goey, A. Sadiki, J. Janicka, Combust. Theor. Model. 22 (2018) 998-1032.

[25] E. Hairer, S.P. Nrsett, G. Wanner, Solving Ordinary Differential Equations I, Springer Berlin Heidelberg, 2008.
[26] E. Hairer, G. Wanner, Solving Ordinary Differential Equations II, Springer-Verlag GmbH, 2010.

[27] K.R. Jackson, Dverk, netlib implementation of verner 6(5), 1985. https://netlib.sandia.gov/ode/ dverk.f Accessed: 08-10-2018.

[28] A.L. Breiter, V.M. Mal'tsev, E.I. Popov, Combust. Explos. Shock Waves 13 (1977) 475-485. 